\title{
ANALISIS PERENCANAAN STRATEGI UNTUK MEMPERTAHANKAN EKSISTENSI PERUSAHAAN DALAM MEWUJUDKAN KEUNGGULAN BERSAING
}

\section{Anindyta Mauliandari dan Mahfudz}

Universitas Diponegoro Semarang, Indonesia

Email: anindytamauliandari10@gmail.com dan mahfudz.fe.undip@gmail.com

\section{Abstract}

The role of family companies in the economy in Indonesia has a big role. According to a survey that has been conducted in several studies, it is also said that many family companies fail to pass up to three successions. The purpose of this study is to identify and analyze the factors that have an impact on the company's strategic planning so as to create a competitive advantage. This study analyzes the factors that influence the company to survive up to the third generation, and are able to formulate strategic plans that can excel in the competition. This study uses a qualitative method with a case study approach as a research tool. The analysis of the results of the information results then mapped the factors that appear and then builds the development of a soft model of the factor mapping. The interview process involves the third generation as a succession to the previous generation, employees who have worked from the previous generation and employees who work in the third generation. The results showed that there are four factors that influence strategic planning that can make the company survive into the third generation. The four factors are managerial factors, organizational culture, strategic planning and company performance.

Keywords: succession; competitive advantage; strategic planning; strategic planning factors; qualitative methods

\section{Abstrak}

Peran perusahaan keluarga dalam ekonomi di Indonesia memiliki peran yang besar. Menurut survey yang sudah dilakukan dibeberapa penelitian juga mengatakan bahwa banyak perusahaan keluarga yang gagal dalam melewati hingga tiga suksesi. Tujuan dari penelitian ini adalah mengidentifikasi dan menganalisis faktor- faktor yang berdampak dalam merencanakan strategi perusahaan sehingga mampu menciptakan keunggulan bersaing. Penelitian ini menganalisis faktor-faktor yang mempengaruhi perusahaan hingga mampu bertahan sampai dengan generasi ketiga, dan mampu menyusun perencanaan strategi yang bisa unggul dalam persaingan. Penelitian ini menggunakan metode kualitatif dengan pedekatan studi kasus sebagai alat penelitianya. Analsis hasil dari hasil informasi kemudian dipetakan faktor yang dimunculkan lalu membangun pengembangan soft model dari pemetaan faktor tersebut. Proses wawancara melibat generasi ketiga selaku suksesi generasi sebelumnya, karyawan yang telah bekerja dari generasi sebelumnya dan karyawan yang bekerja di generasi ketiga. Hasil penelitian menunjukkan ada empat faktor

$\begin{array}{ll}\text { How to cite: } & \text { Mauliandari, A. dan Mahfudz (2021 Analisis Perencanaan Strategi untuk Mempertahankan Eksistensi } \\ & \text { Perusahaan dalam Mewujudkan Keunggulan Bersaing), 6(4). http://10.36418/syntax-literate.v6i4.2468 } \\ \text { E-ISSN: } & \text { 2548-1398 } \\ \text { Published by: } & \text { Ridwan Institute }\end{array}$


yang mempengaruhi perencanaan strategi yang dapat menjadikan perusahaan tersebut bertahan hingga ke generasi ketiga. Keempat faktor tersebut dalah faktor manajerial, budaya organisasi, perencanaan strategi dan kinerja perusahaan.

Kata kunci: suksesi; keunggulan bersaing; perencanaan strategi; faktor perencanaan strategi; metode kualitatif

\section{Pendahuluan}

Bisnis keluarga memiliki arti yang begitu bermakna dan menciptakan peranan pada petumbuhan perekonomian di suatu negara. Sebuah bisnis dapat dikatakan bahwa bisnis tersebut merupakan bisnis keluarga (Family Business) apabila dalam operasi bisnis dan kepemilikan tersebut mengikutsertakan atau melibatkan anggota keluarga. Ada batasan lain yang diberikan tentang perusahaan yaitu suatu perusahaan dikatakan sebagai perusahaan keluaraga apabila terbentuk dari beberapa anggota keluarga (dua atau lebih) yang berperan mengawasi keuangan perusahaan, penelitian mengatakan bahwa suatu organisasi dapat dikatakan perusahaan keluarga jika ada paling sedikit dua generasi yang terlibat dalam keluarga tersebut dan generasi tersebut juga ikut berpengaruh dari kebijakan perusahaan (Ward, 1997).

Setiap pemimpin dari setiap generasi memiliki pengaruh terhadap perkembangan bisnis keluarga melalui suksesi kepemimpinan yang diterapakan. Karena suksesi kepemimpinan merupakan salah satu hal yang mempengaruhi keberlangsungan perusahaan keluarga. Konflik yang biasa dimunculkan dalam suksesi kepemimpinan dalam perusahaan keluarga adalah pendiri perusahaan masih memiliki peran sebagai penggerak bisnis utama dan anggota keluarga yang kemudian ikut berperan dalam perusahaan. Salah satu faktor yang membedakan pada generasi baru adalah memiliki cara pandang yang berbeda dikarenakan pada umumnya memiliki jenjang pendidikan yang lebih tinggi dari generasi sebelumnya. Dalam menentukan keberlangsungan perusahaan untuk jangka panjang dari generasi ke generasi diperlukan perencanaan suksesi sebagai dasar menentukan langkah-langkah yang dipersiapkan (Soedibyo, Suryoatmojo, Robandi, \& Ashari, 2012).

Peran perusahaan keluarga dalam ekonomi di Indonesia memiliki peran yang besar. Menurut survey yang sudah dilakukan dibeberapa penelitian juga mengatakan bahwa banyak perusahaan keluarga yang gagal dalam melewati suksesi ini. Oleh sebab itu pada penelitian ini akan membahas secara deskriptif mengenai perencanaan suksesi pada perusahaan keluarga dalam mempertahankan eksistensi perusahaan sehingga mampu menciptakan keunggulan bersaing.

Dengan latar belakang permasalahan dan rumusan permasalahan penelitian tersebut memliki tujuan penilitian yaitu mengidentifikasi dan menganalisis faktorfaktor yang berdampak dalam merencanakan startejik perusahaan sehingga mampu menciptakan keunggulan bersaing. Selain itu pada penelitian ini bertujuan untuk mengetahui beberapa hal dalam pertanyaan penelitian yaitu:

1. Mengidentifikasi dan menganalisis faktor-faktor yang berdampak dalam perencanaan startejik perusahaan. 
2. Mengidentifikasi dan menganalisis dampak dari perencanaan startejik perusahaan terhadap kinerja.

3. Mengidentifikasi dan menganalisis stratejik perusahaan dalam menciptakan keunggulan bersaing.

Pada suatu organisasi untuk mewujudkan keberhasilan tujuan organisasi dipengaruhi oleh manajerial skill yang dimiliki oleh manajer. Suatu perusahaan akan mengalami kompetensi dalam perencanaan strategi yang merupakan suatu penentu derajat suatu perusahaan tersebut. Dalam proses perencanaan strategi ditentukan oleh sumber manajerial tertentu. Faktor manajerial menjadi salah satu faktor yang berpengaruh pada perencana strategis dan menajdi salah satu kenyakinan antara perencanaan dan kinerja (Mussardo, 2019).

Kemampuan pemimpin perusahaan dalam menerapkan perencanaan strategis antara lain adalah pengetahuan dan keahlian dalam memimpin perusahaan. Keyakinan akan pengaruh perencanaan strategi dan kinerja dideskripsikan dengan seberapa mungkin pemimpin perusahaan dapat membuat perencanaan strategis sehingga dapat meningkatkan kinerja yang nantinya akan berpengaruh terhadap keunggulan bersaing (Jumingan, 2017).

Beberapa nilai yang ada di dalam budaya perusahaan yang dapat membentuk sebuah sikap dan perilaku yang menguntungkan adalah nilai, aturan dan kepercayaan. Oleh karena itu di dalam karir seseorang dan di sebuat komitmen organisasi , budaya perusahaan sangat berpengaruh. Karena memiliki kesamaan mengenai tipologi dimensi dari budaya organisasi (Hogan \& Coote, 2014).

(Primaningtyas, 2012) mengatakan bahwa budaya perusahaan menciptakan dampak yang sangat signifikan di organisasi mereka, yaitu pada tanggung jawab dan komitmen karyawan. Dalam menciptakan budaya perusahaan, diperlukan tanggung jawab serta komitmen dari karyawan berserta perilakunya. Hal tersebut juga pengaruh dari sikap dan perilaku dari pemimpin perusahaan yang telah diperlihatkan.

(Wiklund, 1999) menjelaskan salah satu indikator kinerja yang layak dan telah menjadi ukuran dimensi pertumbuhan yang baik adalah pertumbuhan penjualan. Hal tersebut berawal dari adanya kenaikan permintaan produk yang perusahaan tawarkan, kemudian terjadi kenaikan penjualan. Kenaikan penjualan menjadi indikator pertumbuhan yang dipilih sebagai pertumbuhan pangsa pasar (market share). Pertumbuhan pangsa pasar dapat digunakan sebagai alat ukur efektifitas pasar, selain dari penilaian kemampuan perusahaan dalam sebuah pencapaian skala efisiensi dan kekuatan pasar (market power).

Pengertian lain dari perencanaan stratejik menurut (Shrader, Mulford, \& Blackburn, 1989) Perencanaan strategi merupakan suatu perencanaan dalam kurun waktu yang jauh atau dengan kata lain perencanaan jangka panjang yang tertulis , perencanaan tersebut meliputi kesepakatan misi dan tujuan dari perusahaan. Kategori inisiasi proses, aturan tujuan, arti dan akhir dari hubungan, penjelasan dari pelaksanaan stratejik dan tingkat keputusan yang terintergrasi merupakan beberapa dimensi perencanaan stratejik (Astuti, 2019). 
Dalam manajemen mampu mengembangkan perencanaan stratejik pada keunggulan bersaing berkelanjutan ketika manajer dapat mengkreativitaskan dan dapat mengimplementasikan strategi supaya bisa bertahan saat pesaing melakukan peniruan yang mampu menimbulkan faktor hambatan pada jangka panjang (Bharadwaj, Varadarajan, \& Fahy, 1993). Menurut beberapa pakar penelitian, menyimpulkan bahwa perencana dapat mengalahkan non perencana, dimana perusahaan yang mempunyai rencana secara formal lebih menguntungkan atau lebih unggul dibandingkan dari perusahaan yang hanya memiliki rencana informal, alasannya proses dalam penulisan rencana mengharuskan untuk menulis ide dan tujuan yang kemudian dipikirkan secara matang (Shrader et al., 1989). Pendapat ini juga didukung oleh (Pearce, Freeman, \& Robinson Jr, 1987) yang dikutip oleh (Shrader et al., 1989) semakin sulit dan rumit dari sebuah proses penyusunan perencanaan maka semakin baik juga kinerja dari sebuah organisasi atau perusahaan.

Menurut (D'aveni \& Ravenscraft, 1994) menyatakan keunggulan adalah hal yang dinamis dan tidak dapat dipertahankan. Sehingga persaingan yang ada harus dinilai sebagai persaingan dengan dinamika yang tinggi artinya persaingan yang terjadi hari ini belum tentu sama dengan persaingan yang akan datang, oleh sebab itu dengan beberapa hal yang terjadi tersebut persaingan dihadapi dengan beberapa pemikiran strategi (Riyanto, 2018).

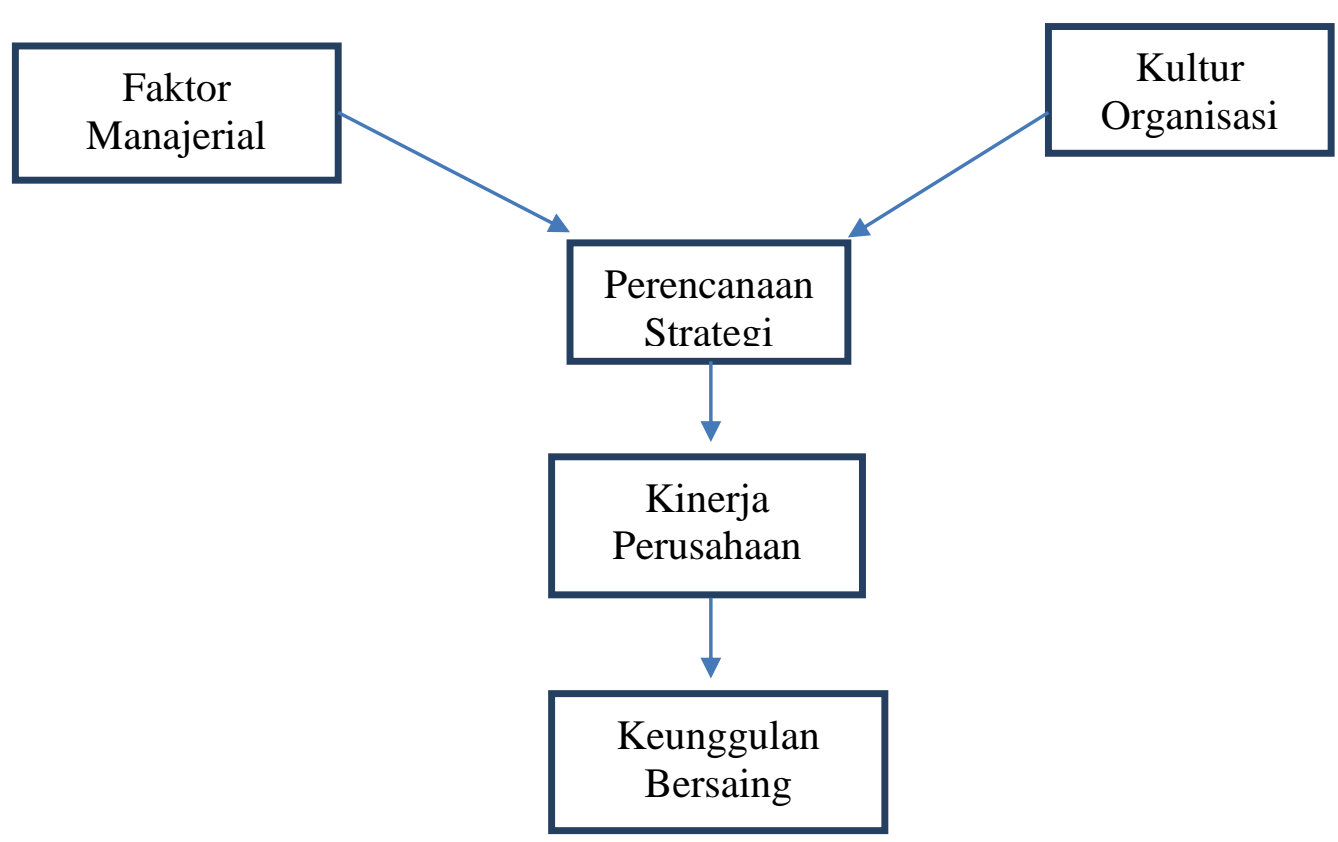

Gambar 1 Kerangka Pemikiran Teoritis

\section{Metode Penelitian}

Penelitian menggunakan desain dan metode penelitian studi kasus, yang studi kasus memberikan nilai tambah pada penelitian mengenai fenomena individual , organisasi, sosial dan politik. Studi kasus juga memungkinkan untuk mempertahankan 
karakteristik holistik dan bermakna dari kehidupan yang nyata. Seperti siklus kehidupan seseorang, proses-proses organisasional dan manajerial dan lain sebagainya. Studi ini dilakukan di CV Mubarok Food Cipta Delcia. Pemilihan lokasi studi ini ditentukan secara sengaja (purposive) dengan alasan bahwa dianggap relevan untuk menggambarkan fenomena hubungan dengan perusahaan yang berdiri dengan beberapa generasi kepemimpinan. Pengumpulan data dilaksanakan mulai bulan Desember 2020 sampai Januari 2021.

Pada penelitian ini menentukan informan menggunakan teknik purposive sampling. Teknik ini digunakan untuk menentukan basis data berdasarkan latar belakang permasalahan dan tujuan studi , sebagai cara untuk memperoleh informasi dan data yang tepat dan akurat sesuai yang dibutuhkan dalam penelitian (Spradley, 1979).

Penentuan informan sangat mempengaruhi pada penelitian kualitatif, karena data dan informasi yang didapatkan dari informan harus memiliki informasi terkait dengan studi pada penelitian ini. Wawancara dilakukan terhadap subjek penelitian yaitu informan yang bersinggungan langsung dengan generasi pertama, kedua dan ketiga. Seperti yang ditunjukkan pada Tabel 1 sebagai berikut:

\section{Tabel 1}

Penentuan Informan

\begin{tabular}{cccl}
\hline No. & Pihak Informan & $\begin{array}{c}\text { Jumlah } \\
\text { Informan }\end{array}$ & \multicolumn{1}{c}{ Keterangan } \\
\hline 1. & Generasi 3 & 2 & $\begin{array}{l}\text { 1 informan sebagai generasi 3 yang } \\
\text { sekarang menjad Direktur Utama } \\
\text { 1 informan sebagai karyawan yang } \\
\text { bekerja di generasi ke 3 }\end{array}$ \\
\hline 2. & Generasi 2 & 2 & $\begin{array}{l}\text { 2 informan yang bekerja sejak generasi } \\
\text { kedua }\end{array}$ \\
\hline & Total & 4 informan & \\
\hline
\end{tabular}

\section{Hasil dan Pembahasan}

Melihat dari pernyataan yang disampaikan oleh informan penelitian menunjukkan bahwa dari generasi kedua dan ketiga memiliki gaya kepemimpinan yang berbeda. Terlebih adanya perbedaan background pendidikan dan karyawan yang dipimpin serta keadaan bisnis yang dijalani pada saat itu. Sehingga terbentuklah gaya kepemimpinan yang bebeda, jika digenerasi kedua masih cenderung sederhana dan di generasi kedua lebih terencana dan generasi memiliki skill kepemimpinan yang mumpuni untuk membangun perusahaan. Maka dapat dlihat bahwa beberapa informasi yang didapatkan dapat peneliti ubah menjadi tiga dimensi dari faktor manajerial yaitu keahlian manajerial, keyakinan manajerial dan profesioanalitas staf. Peneliti melihat bahwa kultur organisasi juga tumbuh di dalam CV Mubarok Food Cipta Delcia. Terlihat dari beberapa budaya perusahaan yang sudah diturunkan dari generasi-generasi sebelumnya yang masih dijalankan hingga saat ini. Kultur organisasi merupakan bagian penting dalam organisasi merupakan integrasi stratejik dari konsep budaya kedalam respon aksi 
kepada perubahan lingkungan. Kemudian dari pernyataan-pernyataan tersebut peneliti menganalisis ketiga dimensi yang ada dalam kultur organisasi yaitu keterlibatan, konsistensi dan komitmen organisasi.

Perencanaan strategi dikhususkan untuk membuat fokus suatu organisasi, dengan tujuan sumber organisasi yang difungsikan dapat secara optimal melayani misi organisasi. dimensi-dimensi perencanaan strategi yang dapat dianalisis : Misi perusahaan, tujuan yang ingin dicapai, pemilihan dan pengembangan strategi.

Perusahaan dapat diukur menggunakan pengukuran yang subyektif dengan berdasarkan pada persepsi staf dan manajer perusahaan yang berasal dari berbagai dimensi pengukuran kinerja perusahaan. Berdasarkan keterangan informan yang didapatkan, maka peneliti melihat secara garis besar aspek-aspek yang muncul yaitu ; efisiensi, efektifitas dan adaptabilitas. kinerja bisnis menggunakan pendekatan seleksi strategis maka akan menjadi fokus pada varibel organisasi, yang dimana organisasi merupakan variabel yang penting dalam menciptakan keunggulan bersaing. Informasi yang didapatkan sesuai dengan informasi bahwa strategi keunggulan bersaing ada beberapa dimensi meliputi sumber daya yang bernilai,tidak mudah ditiru, berbeda dari yang lain dan tidak mudah digantikan.

Berdasarkan hasil analisis transkrip wawancara yang dilakukan dengan informan penelitian dapat diidentifikasikan faktor-faktor dan aspek-aspek yang dipersepsikan oleh peneliti yang tersaji dalam table berikut ini:

Tabel 2

\section{Pemetaan Faktor dan Aspek Perencanaan Stratejik}

\begin{tabular}{|c|c|c|}
\hline No & Faktor & Aspek \\
\hline 1 & $\begin{array}{l}\text { Faktor } \\
\text { Manajerial }\end{array}$ & $\begin{array}{ll}\text { a. } & \text { Keahlian manajerial } \\
\text { b. } & \text { Keyakinan manajerial } \\
\text { c. } & \text { Profesioanlitas staff }\end{array}$ \\
\hline 2 & $\begin{array}{l}\text { Budaya } \\
\text { Organisasi }\end{array}$ & $\begin{array}{ll}\text { a. } & \text { Keterlibatan } \\
\text { b. } & \text { Konsistensi } \\
\text { c. } & \text { Komitmen organisasi } \\
\end{array}$ \\
\hline 3 & $\begin{array}{l}\text { Perencanaan } \\
\text { Stratejik }\end{array}$ & $\begin{array}{l}\text { a. Misi perusahaan } \\
\text { b. Tujuan yang diingin dicapai } \\
\text { c. Pemilihan dan pemgembangan } \\
\text { strategi }\end{array}$ \\
\hline 4 & $\begin{array}{l}\text { Kinerja } \\
\text { Perusahaan }\end{array}$ & $\begin{array}{ll}\text { a. Efisiensi } \\
\text { b. Efektifitas } \\
\text { c. Adaptabilitas }\end{array}$ \\
\hline 5 & $\begin{array}{l}\text { Strategi } \\
\text { Keunggulan } \\
\text { Bersaing }\end{array}$ & $\begin{array}{l}\text { a. Sumber daya yang bernilai, } \\
\text { b. Tidak mudah ditiru } \\
\text { c. } \text { Berbeda dari yang lain }\end{array}$ \\
\hline
\end{tabular}


Analisis Perencanaan Strategi untuk Mempertahankan Eksistensi Perusahaan dalam Mewujudkan Keunggulan Bersaing

\begin{tabular}{|c|c|c|}
\hline No & Faktor & Aspek \\
\hline & & 1. Tidak mudah digantikan \\
\hline
\end{tabular}

(Sumber: Data primer yang diolah, 2020)

Soft model perencanaan stratejik keunggulan bersaing merupakan pengembangan model empiris yang divisualisasikan, menurut faktor-faktor yang menunjukkan aspekaspek yang ditunjukkan dalam menjelaskan perencanaan strategi keunggulan bersaing.

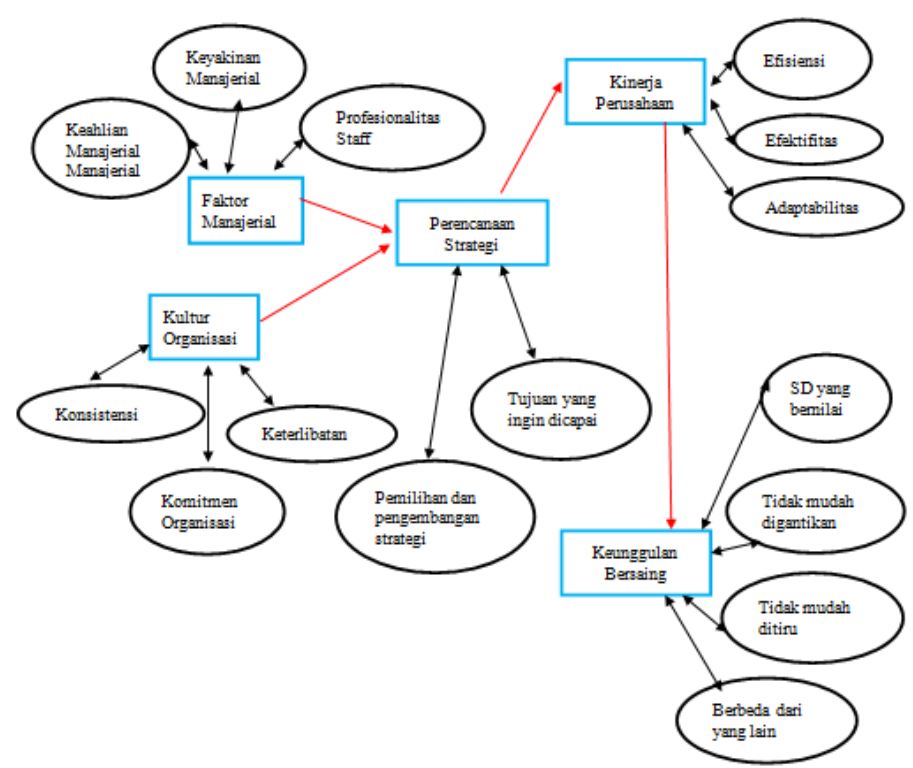

\section{Gambar 2}

Pengembangan Soft Model Perencanaan Stratejik

(Sumber: Dikembangkan untuk penelitian ini, 2020)

Pengembangan soft model yang telah peneliti kembangkan seperti di atas. Dapat dilihat bahwa faktor yang mempengaruhi perencanaan strategi dalam menciptakan keunggulan bersaing di CV. Mubarokfood ada empat faktor yang mempengaruhi yaitu faktor manajerial dan kultur organisasi dapat mempengaruhi perencanaan strategi perusahaan. Di dalam faktor manajerial sendiri memiliki tiga aspek yaitu keahlian manajerial, keyakinan manajerial dan profesionalitas manajerial. Dan kultur organisasi juga memiliki tiga aspek antara lain keterlibatan, konsistensi dan komitmen organisasi.

Perencanaan strategi yang mana memiliki tiga aspek (misi perusahaan, tujuan yang ingin dicapai,dan pemilihan pengembangan strategi) berpengaruh terhadap kinerja perusahaan. Kinerja perusahaan menghasilkan aspek-aspek seperti efisiensi, efektifitas dan adaptabilitas.

Dari keempat faktor tersebut dengan masing-masing aspek, kemudian meciptakan keunggulan bersaing. Tentunya keunggulan bersaing ini memunculkan aspek-aspek seperti sumber daya yang bernilai, tidak mudah ditiru, berbeda dari yang lain dan tidak mudah digantikan. 


\section{Kesimpulan}

Berdasarkan studi dalam penelitian ini bahwa kesuksesan bisnis keluarga tentunya juga dipengaruhi oleh kesiapan perusahaan itu sendiri mempersiapkan generasi penerus dalam melanjutkan suksesi perusahaan. Antara lain kesiapan dari penerus dan perencanaan yang matang. Sehingga bisnis keluarga dapat bertahan dan beradaptasi dengan perubahan zaman. Hal ini juga berpengaruh dalam menciptakan keunggulan bersaing perusahaan. Salah satu faktor yang membedakan pada generasi baru adalah memiliki cara pandang yang berbeda dikarenakan pada umumnya memiliki jenjang pendidikan yang lebih tinggi dari generasi sebelumnya. Penelitian ini membahas secara deskriptif mengenai perencanaan pada perusahaan keluarga dalam mempertahankan eksistensi perusahaan sehingga mampu menciptakan keunggulan bersaing.

Berdasarkan pada hasil studi pada penelitian ini, peneliti mendapatkan tiga hal yang dapat disimpulkan:

1. Penelitian ini menunjukkan hasil bahwa ada empat faktor yang berdampak terhadap perencanaan stratejik perusahaan dalam mempertahankan eksistensi hingga bertahan ke generasi ketiga. Empat faktor tersebu yaitu ; faktor manajerial, kultur organisasi, perencaaan stratejik, kinerja perusahaan dan strategi keunggulan bersaing.

2. Masing-masing faktor tersebut dipetakan dan memiliki aspek-aspek tersendiri di setiap faktornya. Berikut adalah aspek-aspek yang telah dipetakan ;

Tabel 3

Pemetaan Faktor dan Aspek Perencanaan Stratejik

\begin{tabular}{|c|c|c|}
\hline No & Faktor & Aspek \\
\hline 1 & $\begin{array}{l}\text { Faktor } \\
\text { Manajerial }\end{array}$ & $\begin{array}{l}\text { a. Keahlian manajerial } \\
\text { b. Keyakinan manajerial } \\
\text { c. Profesioanlitas staff }\end{array}$ \\
\hline 2 & $\begin{array}{l}\text { Budaya } \\
\text { Organisasi }\end{array}$ & $\begin{array}{l}\text { a. Keterlibatan } \\
\text { b. Konsistensi } \\
\text { c. Komitmen organisasi }\end{array}$ \\
\hline 3 & $\begin{array}{l}\text { Perencanaan } \\
\text { Stratejik }\end{array}$ & $\begin{array}{l}\text { a. Misi perusahaan } \\
\text { b. Tujuan yang diingin dicapai } \\
\text { c. Pemilihan dan pemgembangan strategi }\end{array}$ \\
\hline 4 & $\begin{array}{l}\text { Kinerja } \\
\text { Perusahaan }\end{array}$ & $\begin{array}{l}\text { a. Efisiensi } \\
\text { b. Efektifitas } \\
\text { c. Adaptabilitas }\end{array}$ \\
\hline 5 & Strategi & a. Sumber daya yang bernilai, \\
\hline
\end{tabular}


Analisis Perencanaan Strategi untuk Mempertahankan Eksistensi Perusahaan dalam Mewujudkan Keunggulan Bersaing

\begin{tabular}{llll}
\hline No & Faktor & & \multicolumn{1}{c}{ Aspek } \\
\hline & Keunggulan & b. & Tidak mudah ditiru \\
Bersaing & c. & Berbeda dari yang lain \\
& d. & Tidak mudah digantikan \\
\hline
\end{tabular}

(Sumber: Data primer yang diolah, 2020)

3. Berdasarkan pada faktor dan aspek yang sudah ditemukan dalam studi ini peneliti membuat visualisasi dari faktor dan aspek yang mempengaruhi perencanaan stratejik perusahaan dalam mempertahankan eksistensnya ke dalam sebuah soft model. 


\section{BIBLIOGRAFI}

Astuti, Enny Diah. (2019). Perencanaan Strategi Bisnis dengan Penerapan Corporate Entrepreneurship dalam Meningkatkan Kinerja Perusahaan Studi Empiris Pada: UKM Industri Pakaian Jadi Kota Bekasi. Jurnal Lentera Bisnis, 8(1), 6-17. Google Scholar

Bharadwaj, Sundar G., Varadarajan, P. Rajan, \& Fahy, John. (1993). Sustainable competitive advantage in service industries: a conceptual model and research propositions. Journal of Marketing, 57(4), 83-99. Google Scholar

D'aveni, Richard A., \& Ravenscraft, David J. (1994). Economies of integration versus bureaucracy costs: does vertical integration improve performance? Academy of Management Journal, 37(5), 1167-1206. Google Scholar

Hogan, Suellen J., \& Coote, Leonard V. (2014). Organizational culture, innovation, and performance: A test of Schein's model. Journal of Business Research, 67(8), 1609-1621. Google Scholar

Jumingan, Jumingan. (2017). Faktor-Faktor Yang Mempengaruhi Intensitas Perencanaan Strategik Dan Kinerja Finansial Pada Bank Perkreditan Rakyat Di Jawa Tengah. Jurnal Bisnis Dan Manajemen (Journal of Business and Management), 15(2), 23-48. Google Scholar

Mussardo, G. (2019). 済無No Title No Title. Statistical Field Theor, 9(53), 16891699. https://doi.org/https://doi.org/10.1017/CBO9781107415324.004

Pearce, John A., Freeman, Elizabeth B., \& Robinson Jr, Richard B. (1987). The tenuous link between formal strategic planning and financial performance. Academy of Management Review, 12(4), 658-675. Google Scholar

Primaningtyas, Metta. (2012). Pengaruh Aksesibilitas, Atribut Fisik, Kesehatan Lingkungan Dan Fasilitas Publik Terhadap Kepuasan Bermukim (Studi Kasus pada PT. Armada Hada Graha Magelang). Jurnal Sains Pemasaran Indonesia (Indonesian Journal of Marketing Science), 11(3), 283-300. Google Scholar

Riyanto, Slamet. (2018). Analisis Pengaruh Lingkungan Internal dan Eksternal terhadap Keunggulan Bersaing dan Kinerja Usaha Kecil Menengah (UKM) di Madiun. JMBI UNSRAT (Jurnal Ilmiah Manajemen Bisnis Dan Inovasi Universitas Sam Ratulangi)., 5(3). Google Scholar

Shrader, Charles B., Mulford, Charles L., \& Blackburn, Virginia L. (1989). Strategic and operational planning, uncertainty, and performance in small firms. Journal of Small Business Management, 27(4), 45. Google Scholar

Soedibyo, Soedibyo, Suryoatmojo, Heri, Robandi, Imam, \& Ashari, Mochamad. (2012). Optimal Design of Hydrogen Based/Wind/Microhydro Using Genetic Algorithm. Telkomnika (Telecommunication Computing Electronics and Control), 10(4), 695- 
Analisis Perencanaan Strategi untuk Mempertahankan Eksistensi Perusahaan dalam Mewujudkan Keunggulan Bersaing

702. Google Scholar

Spradley, James P. (1979). Interviewing an informant. In The Ethnographic interview. Google Scholar

Ward, John L. (1997). Growing the family business: Special challenges and best practices. Family Business Review, 10(4), 323-337. Google Scholar

Wiklund, Johan. (1999). The sustainability of the entrepreneurial orientationperformance relationship. Entrepreneurship Theory and Practice, 24(1), 37-48. Google Scholar

\section{Copyright holder:}

Anindyta Mauliandari dan Mahfudz (2021)

First publication right:

Journal Syntax Literate

This article is licensed under:

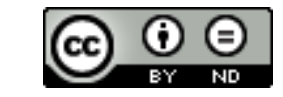

